\title{
The prediction of bereavement outcome: Development of an integrative risk factor framework
}

\author{
Margaret Susan Stroebe ${ }^{\mathrm{a}, *}$, Susan Folkman ${ }^{\mathrm{b}}$, Robert O. Hansson ${ }^{\mathrm{c}}$, Henk Schut ${ }^{\mathrm{a}}$ \\ ${ }^{a}$ Department of Clinical Psychology, Utrecht University, Heidelberglaan 1, 3508 TC Utrecht, The Netherlands \\ ${ }^{\mathrm{b}}$ Osher Center for Integrative Medicine, University of California, San Francisco, USA \\ ${ }^{\mathrm{c}}$ Department of Psychology, University of Tulsa, 600 S. College Avenue, Tulsa, OK 74104, USA
}

Available online 27 July 2006

\begin{abstract}
We propose an integrative risk factor framework to enhance understanding of individual differences in adjustment to bereavement and to encourage more systematic analysis of factors contributing to bereavement outcome (e.g., examination of interactions between variables and establishing pathways in the adaptation process). The examination of individual differences in adaptation to bereavement is essential for practical (e.g. targeting high risk individuals for intervention) and theoretical (e.g. testing the validity of theoretical claims about sources of differences) purposes. And yet, existing theoretical approaches have not led to systematic empirical examination and empirical studies in the current literature are fraught with shortcomings. Derived from Cognitive Stress Theory [Lazarus, R. S. \& Folkman, S. (1984). Stress, appraisal, and coping. New York: Springer] and the stressor-specific Dual Process Model of Coping with Bereavement [Stroebe, M. S., \& Schut, H. A. W. (1999). The dual process model of coping with bereavement: Rationale and description. Death Studies, 23, 197-224], the framework incorporates an analysis of stressors, intra/interpersonal risk/protective factors, and appraisal and coping processes that are postulated to impact on outcome. Advantages of using the approach are outlined. Challenges in undertaking such research are addressed.
\end{abstract}

(C) 2006 Elsevier Ltd. All rights reserved.

Keywords: Grief; Coping; Health; Bereavement; Factor framework

\section{Introduction}

The impact of the death of a loved one on the mental and physical health of the surviving family member or friend has been widely investigated, and there is ample evidence of its deleterious effects (Archer, 1999; Parkes, 1996). Bereaved persons are at elevated risk of developing a variety of mental and physical health problems that may persist long

\footnotetext{
${ }^{*}$ Corresponding author.

E-mail address: M.S.Stroebe-Harrold@FSS.UU.NL (M.S. Stroebe).
}

after the loss has occurred. A minority of individuals are vulnerable to complications in the grieving process itself, for example, chronic grief, which is characterized by protracted grief and prolonged difficulty in normal functioning (Bowlby, 1980; Parkes \& Weiss, 1983). Although small in terms of absolute numbers, even the risk of mortality for bereaved persons is higher than for non-bereaved persons of equivalent age and gender (Stroebe \& Stroebe, 1993).

Nevertheless, there is considerable variability among surviving family members' and friends' responses to loss. While some bereaved persons 
suffer from the ailments outlined above and most experience intense grief when a loved one dies, many individuals adapt well over the course of bereavement, with some even showing few signs of distress (Bonanno, Wortman, \& Nesse, 2004; Lucas, Clark, Georgellis, \& Diener, 2003). Given such diversity, it becomes important to establish who is at risk of the diverse detrimental effects. ${ }^{1}$

It is critical to identify those persons who are likely to suffer from the more severe consequences of bereavement, because professional help needs to be channelled to those who need and will benefit from it (Schut, Stroebe, van den Bout, \& Terheggen, 2001). There is no empirical evidence that provision of routine psychological intervention simply because someone has suffered bereavement is effective (Jordan \& Neimeyer, 2003; Schut et al., 2001). This conclusion is endorsed by leading experts: According to Raphael, Minkov, and Dobson (2001) "there can be no justification for routine intervention for bereaved persons in terms of therapeutic modalities - either psychotherapeutic or pharmacological" (p. 587).

The study of individual differences in adaptation to bereavement is also valuable at the theoretical level. For example, with respect to examination of individual differences, Stroebe and Schut (2001) explained: "The study of risk factors ... plays an important role in developing and testing theoretical explanations of the health impact of bereavement. Because theories of bereavement identify situational or personal characteristics likely to be associated with poor bereavement outcome, the study of these risk factors can be used as a method of testing such theoretical predictions." (pp. 349-350).

Much research to date investigating individual differences in bereavement outcome has followed such a "risk factor" approach. Bereavement researchers have used the term risk factor to signify the identification of situational and personal characteristics likely to be associated with increased vulnerability across the spectrum of bereavement outcome variables (Stroebe \& Schut, 2001). In general, as Last (1995) noted, the term risk factor has been used somewhat loosely, covering (1)

\footnotetext{
${ }^{1}$ For simplicity, we refer to the broad spectrum of negative effects as "health consequences", without linking specific outcomes to different variables. Ultimately, expansion of outcomes and greater complexity will be mandatory: specific reactions to bereavement are likely to have unique sets of predictors (e.g., a specific relationship between immune function and major depressive syndrome, Zisook et al., 1993).
}

attributes that are associated with increased probability of a certain outcome (i.e. not necessarily causal); (2) ones that increase the probability of the occurrence of the outcome (i.e. determinants); and (3) determinants that can be modified by intervention to reduce probability of occurrence of the outcome (referred to as modifiable risk factors). Somewhat confusingly, all three types of meanings have been used in bereavement research.

Analysis in terms of risk factors alone may be too limited. Recently, a growing body of literature has focused on protective, health-promoting factors and strategies (Bonanno, Wortman, \& Nesse, 2004; Folkman, 2001), which are also important in bereavement outcome (e.g., secure attachment; positive reappraisal). Whether protective and risk factors are two ends of the same continuum, or orthogonal forces, is a matter of debate (further exploration is beyond the scope of this article). Here we define a risk factor as a variable that when present, increases the likelihood of poor outcome; and a protective factor as a variable that when present, increases the likelihood of good outcome. Both types of variables are included in the model, but, again for the sake of simplicity, we frequently subsume the latter factors under the former label.

A risk factor approach has typically not incorporated processes that impede or facilitate adjustment to a loved one's death. Are there "healthy" versus "unhealthy" ways of going about grieving; can the way of coping itself be considered a risk factor? There has been little integration of pathways (systematically including mediating and moderating variables) between experiencing the stressor of bereavement and the outcome to it in this type of research. Furthermore, researchers have tended to neglect the impact on adjustment of secondary stressors associated with bereavement (e.g., trouble managing one's legal or financial affairs).

With respect to the body of empirical knowledge: numerous studies have investigated a variety of factors associated with differences in bereavement outcome over the past decades (for reviews of negative consequences, see Archer, 1999; Parkes, 1996; Sanders, 1999; Stroebe \& Schut, 2001; for review of personal growth and interpersonal consequences, see Schaefer \& Moos, 2001). Often such studies select a few or one specific factor(s) to examine, for example, the type of relationship to the deceased - child, spouse, or parent (Sanders, 1999), or cause of death (Cleiren, 1993). Thus, little is known about the relative impact of different factors, 
and only rarely have investigators addressed interactions between individual risk factors. For example, we need to learn the extent to which a specific risk factor (e.g. having a ruminative coping style) increases vulnerability to a particularly horrendous type of loss (e.g. witnessing the violent death of one's own child).

Some risk factor studies omit control groups, making it unclear whether differences in bereavement outcome reflect main or interaction effects. For example, gender differences in depression among widows and widowers have been interpreted as indicating greater symptomatology among widows than widowers, since, in absolute terms, widows have higher depression levels than widowers. However, when levels for non-bereaved controls are taken into account, widowers usually show relatively greater symptomatology (compared with married men) than widows (compared with married women) (Stroebe, Stroebe, \& Schut, 2001). Exemplars exist in the medical/epidemiological literature that incorporate rigorous design methodologies, enabling examination of relative risk in exposed versus unexposed populations (e.g. Li et al., 2004).

It is also noteworthy that, despite some investigation of resilience noted earlier, comparatively little research on risk/protective factors has been conducted in recent years. Earlier investigations of many risk factors thus lack the methodological and statistical sophistication that is available to contemporary investigators (Stroebe \& Schut, 2001).

We have argued the need for a systematic, scientific approach to the examination of risk factors. A number of researchers have attempted, first, to systematically categorize types of risk factors, and second, two research teams have developed so-called "integrative theories" for the prediction of bereavement outcome. With respect to the development of categorization systems, the work of Parkes (1972, 1986) has been prominent. Parkes classified determinants of outcome to bereavement in terms of antecedent factors (e.g. previous mental illness), concurrent factors (e.g., age, religion) and subsequent factors (e.g. social isolation). Although this early research stimulated further investigation and led to the development of a "risk index" to assess likelihood of poor bereavement outcome (Parkes \& Weiss, 1983), basically it was assumed that an accumulation of factors (and their extremity) would lead to worse adaptation. Not much focus was placed on the relative weight of each factor or impact of interaction between factors on outcome.
More recently, Stroebe and Schut (2001) provided a systematic review of risk factors in bereavement outcome in terms of situational risk factors (e.g. mode of death), personal risk factors (e.g. personality), and interpersonal risk factors (e.g. social support). This review was limited to partner loss, to a selection of those factors that had been most extensively studied, and with respect to the range of outcomes (it focused on health consequences and distress). Furthermore, their concept of risk factor excluded mediating processes such as coping. Thus, neither of the category systems reviewed so far lend themselves to examination of the relative impact of different risk factors and their interactions, or of mediating pathways in adaptation to bereavement.

Sander's (1989/1999) Integrative Theory of Bereavement is exemplary of a more theoretical risk factor approach to understanding differences in adaptation to bereavement. This theory incorporates five phases, marking "progression toward resolution and homeostasis" (p. 38). The theory describes three entities: (1) the onset, including the death itself, plus internal (e.g. personality) and external (e.g. type of death) mediators; (2) the process of bereavement in terms of the five phases (shock, awareness, conservation-withdrawal, healing, and renewal); and (3) the outcome, in terms of personal growth, no change, or adverse change in health and functioning. As such, the theory not only portrays individual differences across the course of grief, but also incorporates analysis of the diversity of situations that bereaved persons are confronted with. However, it lacks a detailed, systematic process analysis such as that provided by cognitive stress theory (Lazarus \& Folkman, 1984). For example, it neither describes process in terms of coping mechanisms, nor as a sequence from experience of the stressor (bereavement), through cognitive appraisal and coping to outcome. It also seems true to say that, although Sanders's research on risk factors in general has had high impact in the field, this theoretical analysis has received too little acknowledgement.

Bonanno and Kaltman (1999) identified factors associated with adaptation within the context of their broader integrative perspective on bereavement, a theory designed to provide a new, general psychological perspective for understanding phenomena of bereavement. The four so-called primary components were: the context of the loss, referring to diverse risk factors; the continuum of subjective meanings associated with loss, denoting a broad 
range of appraisals and evaluations; changing representations of the lost relationship over time, which plays a role in the grieving process and the role of coping and emotion regulation processes, which identifies coping strategies that potentially ameliorate or exacerbate the stress of loss. It is not clear on what theoretical basis these four components were selected as "primary"; they were derived from review of different types of theories. Furthermore, although Bonanno and Kaltman (1999) assumed that these factors interact with one another and/or that one factor moderates another in affecting outcome, systematic or conceptual representation of potential relationships among the four groups of components was not provided, making it difficult, for example, to define pathways associated with differential outcomes.

In our view, bereavement theories to date have provided a good starting point for the identification of risk factors. However, as we move forward, decisions regarding which variables to include and which to exclude in theories of adjustment to bereavement will benefit from a more comprehensive, systematic empirical approach based on unasked or unanswered questions raised in the theoretical and empirical research of the last 25 years.

Ideally, such a framework should achieve a number of objectives. It should guide and generate empirical research on individual differences in adaptation to bereavement. It should provide more comprehensive, systematic exploration of risk variables and processes associated specifically with bereavement outcomes. It should highlight pathways and interactions between variables that are feasible to study. Finally, it should also provide a basis for selectively testing and refining existing bereavement theories and improving their predictive potential with respect to bereavement outcomes. Clearly, the task of formulating such a model needs to be progressive and cumulative. Thus, the purpose of this paper is to propose a risk factor framework as a first step in the direction of further integration. We review studies that provide preliminary empirical support for the model.

\section{Description of the framework}

The integrative risk factor framework builds on a generic cognitive stress, appraisal and coping model (Lazarus \& Folkman, 1984), and a compatible bereavement-specific stress model, namely, the Dual Process Model of Coping with Bereavement
(Stroebe \& Schut, 1999). As we illustrate later, major bereavement theories, such as attachment theory (e.g. Bowlby, 1980), are also applicable within the general framework.

Lazarus and Folkman (1984; see also Folkman, 2001, Fig. 25/1\&2) included a schematic description of their model of the stress-coping-outcome process. According to this approach, the stress experienced in a given situation is determined through an evaluative process referred to as cognitive appraisal. The appraisal process begins with an evaluation of the personal significance of the situation. Does the situation pose harm, threat, or challenge to the person's valued goals and well-being? Does the situation violate expectations that matter? The appraisal process also includes an evaluation of the demands of the situation, including instrumental demands and demands caused by the need to regulate emotions. These demands are evaluated in relation to resources and options for coping. Do the demands of the situation tax or exceed the person's resources for coping? Are there viable options for regulating emotion and managing the underlying problem? Stress occurs in situations that are appraised as personally meaningful, with demands that tax or exceed resources, and that present few viable options for coping. Stress appraisals generate distress emotions, and if the stress appraisals and distress persist over time, adverse effects on physical health would also be expected. Thus, following this model, to understand individual differences in bereavement outcome, we need to define and analyse the bereavement-related stressors people experience; their appraisals of meaning, demands and resources in relation to those stressors; and their coping processes.

The Dual Process Model defines two types of stressor that grieving people have to deal with, namely, those that are loss- versus restorationoriented. Loss-oriented stressors are those relating to some aspect of the loss experience itself. Restoration-oriented stressors are secondary stressors that are also consequences of bereavement. Both orientations are sources of upset and stress, and are involved in the coping process. The model specifies a dynamic coping process of oscillation in dealing with loss-oriented and restoration-oriented stressors, a regulatory process that distinguishes this model from others. It is proposed that a bereaved person will alternate between coping with the two types of stressors. At times the person will confront and dwell on aspects of loss (or restoration) and at 
other times avoid them. Oscillation between the two (and at times, taking respite from the arduous coping process) is necessary for adaptation (the structural components of the model are depicted in Stroebe \& Schut, 1999, Fig. 1).

The emerging framework based on the cognitivestress and dual process perspectives is depicted in Fig. 1. As can be seen, following the broad parameters of cognitive-stress theory, there are five inter-linked elements in the framework that combine to describe and determine sources of individual differences in adjustment to bereavement, namely, Category A: The nature of the stressor; Category B: Interpersonal resources; Category C: Intrapersonal resources; Category D: Appraisal and coping processes; Category E: Outcomes. Pathways are also depicted in Fig. 1 and variables listed within each category. These variables have been derived from direct examination of empirical research investigations of these variables, risk factor specific reviews and other sources that discuss individual differences in adaptation (e.g., Archer, 1999; Bowlby, 1980; Parkes, 1972, 1986, 1991; Sanders, 1999; Stroebe \& Schut, 2001; Walter, 1999).

We do not provide exhaustive description of the relevant studies here. As noted already, further investigation is indicated for many variables. It is sometimes difficult to estimate the extent to which a given variable is a generic risk factor that affects a bereaved sample any differently than it would the general population. Establishing this is important for theoretical purposes, for example, to ascertain whether social support operates as a buffer in bereavement. It is also important for purposes of establishing whether bereaved persons with a given risk factor, such as low support, are at greatest risk of health deterioration following bereavement (because only bereavement-specific effects increase the magnitude of health deterioration) and consequently for predicting differential efficacy of a social support intervention. Inclusion of the variables in the framework is, therefore, provisional, and should be subject to revision based on results of further empirical investigations.

We turn now to the description of parameters within the integrative framework, and indicate the extent of support from empirical research findings.

\section{The nature of the stressor}

In our case, the precipitating event, the so-called stressor, is the death of a close other and the subsequent state of bereavement. Within this broad, undifferentiated definition of stressor, we have

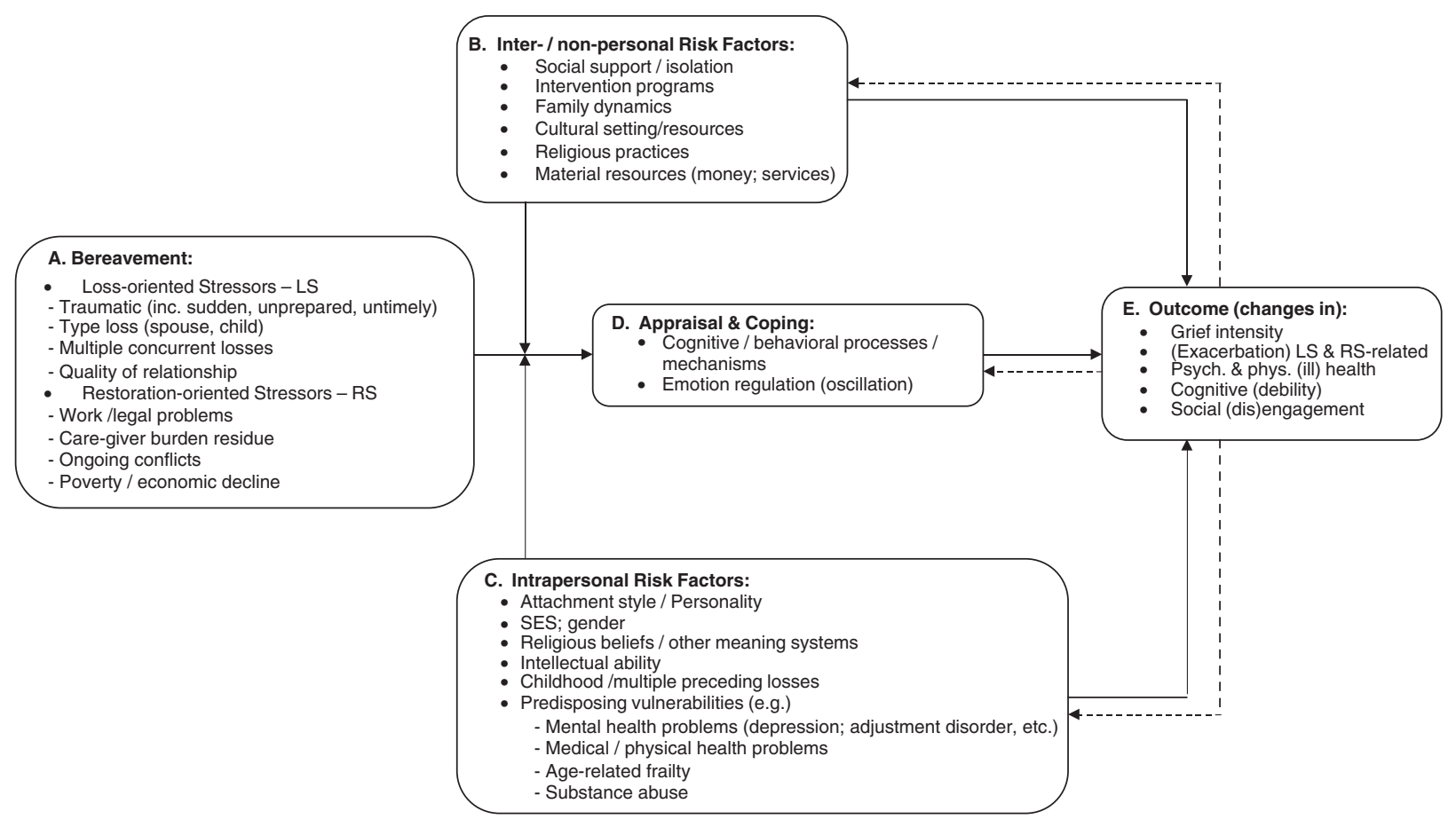

Fig. 1. The integrative risk factor framework for the prediction of bereavement outcome. 
distinguished specific domains of loss- and restoration-oriented stressors.

Within the loss-oriented domain, a bereaved person's reactions will be related directly to the death and/or to the relationship with and personality of the deceased person. For example, the nature of the death event - whether it was traumatic and untimely, or peaceful at the end of a long and fulfilling life - is likely to have a differential impact on the survivor. There is indeed evidence that the nature of the death event contributes to differences in adjustment. Traumatic loss, for example, is typically associated with worse outcome than nontraumatic loss, with risk of Posttraumatic Stress Disorder being particularly high (Raphael \& Martinek, 1997). More research has, however, focused simply on the difference in outcome following sudden loss compared with expected loss. Results are inconsistent: some studies provide evidence that more severe health consequences occur following a sudden rather than expected loss, while others fail to find differences (Stroebe \& Schut, 2001). Stroebe, Stroebe, and Domittner (1988) found that an intrapersonal variable (Category C, see below), namely, internal/external control beliefs, moderated the impact of expectedness on outcome. Unexpected losses resulted in higher levels of depression and somatic complaints only among those who believed they had little control over their lives.

Both quality and type of relationship between the deceased and the surviving person have been investigated. Studies of the quality of (marital) relationship have produced somewhat inconsistent results: there may be some benefits to having had a good relationship (this can also cause distress in bereavement), while ambivalence or dependency have been linked to adjustment difficulties (cf. Carr et al., 2000; Parkes 1996; Prigerson, Maciejewski, \& Rosenheck, 2000). Kinship relationship between the deceased and bereaved persons has been shown to moderate the impact of bereavement on health. Studies have suggested that the loss of an adult child results in even more intense, persistent grief than the loss of a spouse, parent, or sibling (Cleiren, 1993; Nolen-Hoeksema \& Larson, 1999; Sanders, 1999). A recent study by Wijngaards-de Meij et al. (2005) indicated a curvilinear relationship within the category of child loss, with grief among parents who had lost a child up to the age of seventeen increasing with the age of the child, while for those whose child had died above this age, grief was found to have decreasing intensities (although intensities were high for parents irrespective of age).

Deaths by suicide are sometimes considered more difficult than natural deaths for bereaved persons to adjust to, because of the suddenness and stigma surrounding them. Some studies that have compared suicide with natural types of death have failed to find evidence for this (Farberow, GallagherThompson, Gilweski, \& Thompson, 1992). However, Agerbo (2005) recently documented excessive mortality risk (including suicide) following a suicide death. Children may be particularly vulnerable following such a death (Cerel, Fristad, Weller, \& Weller, 1999).

In contrast to these loss-oriented sources of stress, restoration-oriented ones have to do with secondary consequences associated with bereavement. The death of a significant person goes hand-in-hand with a number of changes in everyday life, even possibly some threatening features that also have an impact on adaptation. The Dual Process Model of Coping with Bereavement claims that the bereaved person not only has to deal with grief over the loss of the person him- or her-self, but he/she also has to deal with a wide range of such secondary stressors. For example, in the case of spousal loss, secondary stressors can cover a broad range of problems including difficulties at work (Eyetsemitan, 1998), legal issues arising from the deceased's will, learning how to do tasks the deceased spouse had managed, or poverty due to the loss of the deceased's income (Martikainen \& Valkonen, 1998). Problems can extend to difficulties in social interactions, especially since the very person one would ordinarily turn to for support in such circumstances is missing, and because of the bereaved person's changed identity (e.g. from "wife" to "widow").

What evidence is there on restoration-oriented variables? The work of Lopata (1996) testifies to the range of secondary stressors encountered by American widows, such as financial hardship and social isolation. Social isolation may compound problems after sudden types of death, such as suicides or accidents (Dyregrow, Nordanger, \& Dyregrow, 2003).

The burden of caregiving has been well-researched in recent years (see Hansson \& Stroebe, in press). For example, Schulz et al. (2001) found that high levels of caregiver strain among older people are associated with poorer adjustment (both during the caregiving and bereavement periods) than is the case among caregivers who experienced 
low levels of strain. However, when caregiving has been experienced positively, grief reactions can also be more intense in some respects (Boerner, Schulz, \& Horowitz, 2004).

\section{Interpersonal resources}

A person appraises the personal meaning of the bereavement event in terms of his or her values, goals, and expectations, and in terms of the relationships between the demands of the situation and resources for coping (Lazarus \& Folkman, 1984). Demands of a situation and resources available to deal with them can be classified in two categories, interpersonal (Category B), which we discuss here, or intrapersonal (Category C), discussed next. Interpersonal demands and resources refer to those that originate within the social/environmental context, namely, those that involve factors external to the bereaved person.

Social support is one of the most widely assumed but empirically not so well-founded variables in this category (Stroebe, Schut, \& Stroebe, 2005). Inadequate social support is a general risk factor (Schwarzer \& Leppin, 1989), but as we noted earlier, evidence that it is a bereavement-specific risk factor is not conclusive. A few studies using appropriate designs have reported interactions between bereavement and social support, while others observed no buffering effects.

Participation in a psychological intervention program can also be regarded selectively as an interpersonal resource for persons at high general risk of poor bereavement outcome (e.g., following sudden, traumatic loss; for persons with predisposing risk factors) and for those who are experiencing complications in the grieving process (Schut et al., 2001).

Family dynamics could potentially function as a situational demand, as a resource, or as both over time. For example, families provide the context for meaning-making in bereavement (Winchester-Nadeau, 2001). Also, they are the first-line of support, but over time the constellation of family members can change in size, composition, competence, or motivation to help (Hansson \& Stroebe, in press). The process of change can create its own source of stress. Initial family caregivers may become overwhelmed, requiring renegotiation of care-responsibilities in the family support network (Hansson \& Carpenter, 1994). Such negotiation may not always go smoothly.
There are indications that cultural factors are associated with differences in outcome (Rosenblatt, 2004). Differences in rituals across cultures could be a significant factor and specific ones, such as narrating the deceased's story, have been integrated into therapies (Neimeyer \& Mahoney, 1995). Empirical studies examining the impact of rituals on bereavement outcome are scarce, although there is some evidence that they are helpful for children (Fristad, Cerel, Goldman, Weller, \& Weller, 2001).

\section{Intrapersonal resources}

Major intrapersonal resources, also listed in Fig. 1 (Category C), refer to characteristics intrinsic to the bereaved person him/herself. A secure attachment style may be regarded as a resource in the sense that it is associated with better bereavement adjustment than the insecure attachment styles and some studies support this assumption (e.g. Stroebe, Stroebe, \& Schut, 2005; Wijngaards-de Meij, submitted manuscript). Further research is needed to establish whether secure attachment actually buffers individuals against the impact of bereavement, or whether the patterns reflect a main effect independent of bereavement, since securely attached persons in general enjoy better health than insecure ones (Shaver \& Tancredy, 2001).

It seems plausible that individuals with welladjusted personalities would deal with loss better than the less well-adjusted (possibly reflecting main-rather than bereavement-specific relationships). In an early study, Vachon et al. (1982) found that persons who remained highly distressed after bereavement were low on ego strength and high on anxiety and guilt proneness. Internal control beliefs seem important, as does high self esteem (Haine, Ayers, Sandler, Wolchik, \& Weyer, 2003; Ong, Bergeman, \& Bisconti, 2005; Stroebe et al., 1988), and optimism has a positive impact on adjustment (Moskowitz, Folkman, \& Acree, 2003; NolenHoeksema \& Larson, 1999).

Predisposing vulnerabilities are also included here. For example, persons who, before bereavement, have suffered from depression might have particular difficulty in adjusting to bereavement, making them more at risk (Raphael et al., 2001). Childhood bereavement has been associated with greater vulnerability in adulthood. Some studies have found that death of a parent during childhood has occurred more frequently among adults with depression than among non-depressed adults, while 
others have argued that it is not an etiological factor (Stroebe \& Stroebe, 1987). The adequacy of the remaining parental care after the death of one parent may be a more powerful predictor of later adjustment than the loss of the parent per se (Luecken \& Appelhans, 2006).

Sociodemographic factors can be considered intrapersonal variables. Socioeconomic status does not appear to moderate the effect of bereavement on health, even though it is positively associated with health in general (i.e., there is no interaction effect, both bereaved and non-bereaved high SES persons have better health than those with low SES; Stroebe \& Stroebe, 1987). By contrast, gender appears to have bereavement-specific effects: not only is male gender associated with relatively greater mortality risk in the general population, but widowers have relatively higher rates than widows, compared with their married counterparts (Stroebe et al., 2001). The gender differences in mortality of the widowed seem mirrored in other consequences, such as depression (Lee, DeMaris, Bavin, \& Sullivan, 2001), but different patterns have been found among parents, with mothers showing even higher vulnerability than fathers (Kreicbergs et al., 2004).

Many have claimed that younger bereaved persons are more vulnerable to negative bereavement consequences than the older and some studies have supported this (Archer, 1999). Such simple comparisons, like those between the genders, detract from understanding the unique natures and different contexts of bereavement in younger versus older life (Hansson \& Stroebe, in press). For example, causes of death change in late life (becoming more chronic, predictable, less traumatic); there is also greater likelihood of economic insecurity and of pre-bereavement physical frailty among elderly bereaved.

In line with research on the benefits of religion in coping with life events in general (Pargament, 1997), some investigators have reported positive associations between religiosity and bereavement outcome. Other studies, however, show either no or weak differences between more versus less religious persons, or even worse adjustment among the more religious bereaved (Stroebe, 2004). This variable needs further investigation.

\section{Coping and appraisal}

It is important to include the coping process in an analysis of individual differences in adjustment to bereavement. Although Folkman (2001) cautioned that "coping may have a relatively small influence on adjustment and recovery compared to factors such as the timing and nature of the death, history, and personality" (p. 564), she went on to note "Nonetheless ... coping is important because it is one of the few factors influencing bereavement outcomes amenable to brief interventions" (p. 564). Furthermore, coping mediates between stressors and outcomes, so to understand processes of adjustment, we need to include coping.

The notions of primary (assessment of stressfulness of a situation) and secondary (assessment of coping resources and options) appraisal are central in the analysis of coping: The person appraises the personal significance of the event and the options for coping (Category D). Coping is understood as "constantly changing cognitive and behavioral efforts to manage specific external and/or internal demands that are appraised as taxing or exceeding the resources of a person" (Lazarus \& Folkman, 1984, p. 14). An additional parameter can be drawn from the Dual Process Model: the coping process entails oscillation between appraising and dealing with both loss and restoration types of stressors. Oscillation denotes a process of confrontation and avoidance in dealing with any specific stressor associated with the bereavement situation. Oscillation is considered a fundamental regulatory process for adaptation (too exclusive a focus on either lossor restoration-oriented stressors will not lead to healthy adaptation to loss).

What evidence is there that differences in coping account for individual differences in health consequences? There has been little empirical support for the efficacy of "working through" as a strategy for overcoming grief (e.g., Bonanno, 2001; Stroebe et al., 2005; Wortman \& Silver, 2001). Similar doubts are raised by the negative results of studies of emotional disclosure and social sharing (e.g. Pennebaker, Zech, \& Rimé, 2001) and of avoidance (Bonanno, 2001). Recently, Field and colleagues (e.g. Field, Gal-Oz, \& Bonanno, 2003) examined the efficacy of continuing bonds with a deceased person: does it help to retain the tie? Contrary to recent theoretical argumentation (Klass, Silverman, \& Nickman, 1996), retaining bonds was associated with poor adaptation. Other investigators have provided fine-grained analyses of more specific coping strategies. For example, a study by Moskowitz et al. (2003) showed that, controlling for depression, positive affect, which is strongly 
associated with a coping process known as positive reappraisal, leads to lower levels of depressed mood over time. Nolen-Hoeksema and Larson (1999) showed that a ruminative coping style was associated with poorer adaptation to bereavement over time (controlling for levels of grief early on). Finally, research by Boelen (2005) suggests the importance of processes of cognitive (re)appraisal on bereavement outcome, while others have explored meaning-making as instrumental in furthering adaptation (Davis, Nolen-Hoeksema, \& Larson, 1998).

\section{Outcome}

The above features have an impact on outcome (Category E). Outcome may be evaluated on various dimensions: We noted that consequences of bereavement can range from those related to intensity of grief itself, to various mental and physical health debilities. Outcome can also be measured in terms of other factors, for example, cognitive (dis)abilities unrelated to health (e.g., memory loss, Aartsen, van Tilburg, Smits, Comijs, \& Knipscheer, 2004), physiological changes (O'Connor, Allen, \& Kaszniak, 2002), or social re-integration (Dyregrow et al., 2003).

Both "short-term" outcomes (the focus of most risk factor research) and "long-term" outcomes are featured in the framework. Such extension promotes more comprehensive assessment of bereavement outcomes. It seems reasonable to assume that loss-oriented stressors would tend to predict shortterm outcomes (grief intensity, physical and mental illhealth, etc.), while restoration-oriented stressors would tend to better predict long-term (and less reversible) outcomes (impairments such as functional limitations and disabilities). The long-term outcomes, particularly among older people, would likely involve substantial and irreversible physical and mental health outcomes, diminished competence and independence, premature dependency on services and risk for institutionalization (Hansson \& Stroebe, in press). Such hypotheses can be tested in forthcoming research.

\section{Evaluation and application of the framework}

There are advantages to conducting research within the framework. We have shown that variables associated with individual differences in bereavement outcome have typically been examined independently of each other, with too little attention to interactions between variables in the adjustment process. This can lead to faulty conclusions (Wijngaards de Meij et al., 2005). For example, if social support is controlled for in studies of differences between the religious (who have the support of a religious community) and non-religious (who lack such support) on bereavement outcome, it is conceivable that the impact of religious beliefs will disappear. Furthermore, it has often been unclear, even if a particular factor is relevant to outcome, how much of the variance between individuals in bereavement outcome can be specifically attributed to it: how important is it, compared with other factors? By advocating more comprehensive, systematic exploration not only of risk, but also coping variables associated with bereavement outcomes, our integrative framework promotes the assessment of the extent of individual and combined contributions. As Fig. 1 shows, the model also suggests pathways to (mal)adjustment that can be empirically examined. Using such an approach, it should be possible to establish patterns of mediation and moderation relating to bereavement outcome. In addition, one should ultimately be able to systematically catalogue an even wider range of outcomes associated with specific predictors of bereavement outcome.

A further advantage is that the framework is theory-based. Not only is it derived from cognitive stress theory and the bereavement-specific Dual Process model, but a range of other theories can be placed within it. Risk factor research has typically been atheoretical, and as a result, variables are selected for study without a clear rationale. Theoretical formulations provide a rationale for the selection of variables and how they should be empirically tested. It is quite possible that no single theory of bereavement can explain all aspects of the process and outcomes of adjustment (cf. Wijngaards-de Meij et al., 2005). Delineating the boundaries of application of specific theories would be a useful step. For example, the attachment approach (e.g. Bowlby, 1980; Parkes, 2001; Shaver $\&$ Tancredy, 2001) would contribute much in terms of analysis of intrapersonal risks (Category C). It would be possible to compare the relative contributions of insecurity of attachment and the personality variable neuroticism on bereavement outcome. Because these two are somewhat overlapping constructs, an important question is whether attachment style can explain further variance, over 
and above that associated with neuroticism. This would be predicted by attachment theory. Family systems theory (e.g. Winchester-Nadeau, 2001) would place focus on interpersonal risks (Category B). Here, for example, it would be useful to explore the range of demands and resources provided by family systems in relation to bereavement outcome.

\section{Conclusions}

We have argued the need for an integrative, comprehensive framework of adjustment to bereavement to overcome limitations in previous research, prevent faulty conclusions, and to increase our ability to predict bereavement outcome. Fundamental to our approach (and in contrast to most previous investigations) we argue against examination of any specific factor in isolation. For example, while it may be useful for other purposes to focus solely on gender differences in bereavement outcome (e.g. simply to compare rates of morbidity or mortality), when prediction of relative risk of poor bereavement outcome is the concern, it is more useful to look at gender in combination with, say, differences in the types of stressors that bereaved men and women encounter and at differences in their coping strategies. We need to work toward establishing the relative importance of variables within the different categories A-D and the pathways between them. We even still need to establish the importance of the different categories per se: For example, is Folkman (2001) really correct that coping variables account for relatively little variance?

The framework is to be seen as an integral part of a cumulative model-building process, one that is open to revision. For example, we illustrated the categories within the framework by outlining a number of variables associated with outcome. The list of factors included in our outline needs to be critically reviewed based on the findings of more rigorous research. Some factors may need to be extended, others added or deleted. Some of the variables may come to be viewed in different ways (e.g. will poverty stay as a stressor, SES as an intrapersonal risk factor?). A variety of research designs could be applied to test the impact of sets of related variables within the framework. These could complement each other; for example, some could focus on bereavement-specific variables such as grief intensity, while others could determine whether or not variables are bereavement-specific. Designs to examine the latter would call for non-bereaved control groups to establish whether variables show bereavement-specific or general effects (i.e., as indicated by interactions versus main effects).

The framework is likely to be difficult to test as a whole simply because it is so comprehensive. However, it can be useful for determining a focus for empirical investigation and guiding the selection of variables relevant to that focus. Another approach is to use pooled data sets that provide large enough samples and a wide variety of variables. The public release of one large data set from the "Changing Lives of Older Couples" study has enabled access to scholars from all over the world (Carr, Nesse, \& Wortman, 2005). Such research strategies further the type of research advocated here.

Hopefully, the framework we have presented provides stimulus for new research on factors associated with adaptation to bereavement. In our view, this remains one of the most fundamental, most essential but most neglected of all topics. We need to assess risk more accurately and to develop a reliable index to predict outcome to bereavement, based on sound empirical research.

\section{References}

Aartsen, M. J., van Tilburg, T., Smits, C. H., Comijs, H. C., \& Knipscheer, K. C. (2004). Does widowhood affect memory performance of older people? Psychological Medicine, 34, $1-10$.

Agerbo, E. (2005). Midlife suicide risk, partner's psychiatric illness, spouse and child bereavement by suicide or other modes of death: a gender specific study. Journal of Epidemiology and Community Health, 59, 407-412.

Archer, J. (1999). The nature of grief: The evolution and psychology of reactions to loss. London: Routledge.

Boelen, P. (2005). Complicated grief: Assessment, theory, and treatment. Enscede/Amsterdam: Ipskamp.

Boerner, K., Schulz, R., \& Horowitz, A. (2004). Positive aspects of caregiving and adaptation to bereavement. Psychology and Aging, 19, 668-675.

Bonanno, G. (2001). Grief and emotion: A social-functional perspective. In M. Stroebe, R. O. Hansson, W. Stroebe, \& H. Schut (Eds.), Handbook of bereavement research: Consequences, coping, and care (pp. 493-515). Washington, DC: American Psychological Association.

Bonanno, G. A., \& Kaltman, S. (1999). Toward an integrative perspective on bereavement. Psychological Bulletin, 125, 760-776.

Bonanno, G., Wortman, C., \& Nesse, R. (2004). Prospective patterns of resilience and maladjustment during widowhood. Psychology and Aging, 19, 260-271.

Bowlby, J. (1980). Attachment and loss: Vol. 3: Loss: Sadness and depression. London: Hogarth. 
Carr, D., House, J. S., Kessler, R. C., et al. (2000). Marital quality and psychological adjustment to widowhood among older adults: A longitudinal analysis. Journal of Gerontology: Social Sciences, 55B, S197-S207.

Carr, D., Nesse, R. M., \& Wortman, C. (2005). Late life widowhood in the United States. New York: Springer.

Cerel, J., Fristad, M. A., Weller, E. B., \& Weller, R. A. (1999). Suicide-bereaved children and adolescents: A controlled longitudinal examination. Journal of the American Academy of Child and Adolescent Psychiatry, 38, 672-679.

Cleiren, M. (1993). Bereavement and adaptation: A comparative study of the aftermath of death. Washington, DC: Hemisphere.

Davis, C., Nolen-Hoeksema, S., \& Larson, J. (1998). Making sense of loss and benefiting from the experience: Two construals of meaning. Journal of Personality and Social Psychology, 75, 561-574.

Dyregrow, K., Nordanger, D., \& Dyregrow, A. (2003). Predictors of psychosocial stress after suicide. Death Studies, 27, 143-165.

Eyetsemitan, F. (1998). Stifled grief in the workplace. Death Studies, 22, 469-479.

Farberow, N. L., Gallagher-Thompson, D., Gilweski, M., \& Thompson, L. (1992). Changes in grief and mental health of bereaved spouses of older suicides. Journal of Gerontology: Psychological Sciences, 47, P357-P366.

Field, D., Gal-Oz, E., \& Bonanno, G. (2003). Continuing bonds and adjustment 5 years after the death of a spouse. Journal of Consulting and Clinical Psychology, 71, 110-117.

Folkman, S. (2001). Revised coping theory and the process of bereavement. In M. Stroebe, R. O. Hansson, W. Stroebe, \& H. Schut (Eds.), Handbook of bereavement research: Consequences, coping and care (pp. 563-584). Washington, DC: American Psychological Association.

Fristad, M. A., Cerel, J., Goldman, M., Weller, E. B., \& Weller, R. A. (2001). The role of ritual in children's bereavement. Omega, 42, 321-339.

Haine, R. A., Ayers, T. S., Sandler, I. N., Wolchik, S. A., \& Weyer, J. L. (2003). Locus of control and self esteem as stressmoderators or stress-mediators in parentally bereaved children. Death Studies, 27, 619-640.

Hansson, R. O., \& Carpenter, B. N. (1994). Relationships in old age: Coping with the challenge of transition. New York: Guilford.

Hansson, R. O., Stroebe, M. S. (in press). Bereavement in late life: Coping, adaptation and developmental issues. Washington, DC: American Psychological Association.

Jordan, J., \& Neimeyer, R. (2003). Does grief counseling work? Death Studies, 27, 765-786.

Klass, D., Silverman, P.R., \& Nickman, S.L. (Eds.). (1996). Continuing bonds: New understandings of grief. Washington, DC: Taylor \& Francis.

Kreicbergs, U., Valdimarsdóttir, U., Onelöv, E., Henter, J., \& Steineck, G. (2004). Anxiety and depression in parents 4-9 years after the loss of a child owing to a malignancy: A population-based follow-up. Psychological Medicine, 34, $1431-1441$.

Last, J. (1995). A dictionary of epidemiology (3rd ed.). New York: Oxford University.

Lazarus, R. S., \& Folkman, S. (1984). Stress, appraisal, and coping. New York: Springer.
Lee, G. R., DeMaris, A., Bavin, S., \& Sullivan, R. (2001). Gender differences in the depressive effect of widowhood in later life. Journal of Gerontology: Social Sciences, 56B, S56-S61.

Li, J., Johansen, C., Bronnum-Hansen, H., Steenager, E., KochHenriksen, N., \& Olsen, H. (2004). The risk of multiple sclerosis in bereaved parents. Neurology, 62, 726-729.

Lopata, H. Z. (1996). Current widowhood: Myths and realities. Thousand Oaks, CA: Sage.

Lucas, R. E., Clark, A. E., Georgellis, Y., \& Diener, E. (2003). Reexamining adaptation and the set point model of happiness: reactions to changes in marital status. Journal of Personality and Social Psychology, 84, 527-539.

Luecken, L. J., \& Appelhans, B. M. (2006). Early parental loss and salivary cortisol in young adulthood: The moderating role of family environment. Development and Psychopathology, 18, 295-304.

Martikainen, P., \& Valkonen, T. (1998). Do education and income buffer the effects of death of spouse on mortality? Epidemiology, 9, 530-534.

Moskowitz, J. T., Folkman, S., \& Acree, M. (2003). Do positive psychological states shed light on recovery from bereavement? Findings from a 3-year longitudinal study. Death Studies, 27, 471-500.

Neimeyer, R. A., \& Mahoney, M. J. (1995). Constructivism in psychotherapy. Washington: American Psychological Association.

Nolen-Hoeksema, S., \& Larson, J. (1999). Coping with loss. Mahwah, NJ: Erlbaum.

O'Connor, M., Allen, J., \& Kaszniak, A. (2002). Autonomic and emotion regulation in bereavement and depression. Journal of Psychosomatic Research, 52, 183-185.

Ong, A. D., Bergeman, C. S., \& Bisconti, T. L. (2005). Unique effects of daily perceived control on anxiety symptomatology during conjugal bereavement. Personality and Individual Differences, 38, 1057-1067.

Pargament, K. (1997). The psychology of religion and coping. Theory, research, practice. New York: Guilford.

Parkes, C. M. (1972). Bereavement: Studies of grief in adult life (1st ed.). London: Tavistock/Routledge.

Parkes, C. M. (1986). Bereavement: Studies of grief in adult life (2nd ed.). London: Tavistock/Routledge.

Parkes, C. M. (1996). Bereavement: Studies of grief in adult life (3rd ed.). London: Tavistock/Routledge.

Parkes, C. M. (2001). A historical overview of the scientific study of bereavement. In M. Stroebe, R. O. Hansson, W. Stroebe, \& H. Schut (Eds.), Handbook of bereavement research: Consequences, coping, and care (pp. 25-45). Washington, DC: American Psychological Association.

Parkes, C. M., \& Weiss, R. S. (1983). Recovery from bereavement. New York: Basic Books.

Pennebaker, J., Zech, E., \& Rimé, B. (2001). Disclosing and sharing emotion: Psychological, social, and health consequences. In M. Stroebe, R. O. Hansson, W. Stroebe, \& H. Schut (Eds.), Handbook of bereavement research: Consequences, coping, and care (pp. 517-543). Washington, DC: American Psychological Association.

Prigerson, H. G., Maciejewski, P. K., \& Rosenheck, R. A. (2000). Preliminary explorations of the harmful interactive effects of widowhood and marital harmony on health, health service use, and health care costs. The Gerontologist, 40, 349-357.

Raphael, B., \& Martinek, N. (1997). Assessing traumatic bereavements and PTSD. In J. P. Wilson, \& T. M. Keaane 
(Eds.), Assessing psychological trauma and PTSD (pp. 373-395). New York: Guilford.

Raphael, B., Minkov, C., \& Dobson, M. (2001). Psychotherapeutic and pharmacological intervention for bereaved persons. In M. Stroebe, R. Hansson, W. Stroebe, \& H. Schut (Eds.), Handbook of bereavement research: Consequences, coping and care (pp. 587-612). Washington: American Psychological Association.

Rosenblatt, P. (2004). Cross-cultural variation in the experience, expression, and understanding of grief. In D. P. Irish, K. F. Lundquist, \& V. J. Nelsen (Eds.), Ethnic variations in dying, death, and grief (pp. 13-19). Washington, DC: Taylor \& Francis.

Sanders, C. (1999). Grief: The mourning after: Dealing with adult bereavement (2nd ed.). New York: Wiley and Sons.

Schaefer, J. A., \& Moos, R. H. (2001). Bereavement experiences and personal growth. In M. Stroebe, R. Hansson, W. Stroebe, \& H. Schut (Eds.), Handbook of bereavement research: Consequences, coping and care (pp. 145-167). Washington: American Psychological Association.

Schulz, R., Beach, S. R., \& Lind, B. etal. (2001). Involvement in caregiving and adjustment to death of a spouse. Journal of the American Medical Association, 285, 3123-3129.

Schut, H., Stroebe, M., van den Bout, J., \& Terheggen, M. (2001). The efficacy of bereavement interventions: Determining who benefits. In M. Stroebe, R. Hansson, W. Stroebe, \& H. Schut (Eds.), Handbook of bereavement research: Consequences, coping and care (pp. 705-737). Washington: American Psychological Association.

Schwarzer, R., \& Leppin, A. (1989). Social support: a metaanalysis. Psychology and Health, 3, 1-15.

Shaver, P. R., \& Tancredy, C. M. (2001). Emotion, attachment, and bereavement: A conceptual commentary. In M. Stroebe, R. O. Hansson, W. Stroebe, \& H. Schut (Eds.), Handbook of bereavement research: Consequences, coping and care (pp. 63-88). Washington, DC: American Psychological Association.

Stroebe, M. (2004). Religion in coping with bereavement: Confidence of convictions or scientific scrutiny? The International Journal for the Psychology of Religion, 14, 23-36.

Stroebe, W., \& Schut, H. (2001). Risk factors in bereavement outcome: A methodological and empirical review. In M. S. Stroebe, R. O. Hansson, W. Stroebe, \& H. Schut (Eds.), Handbook of bereavement research: Consequences, coping and care (pp. 349-371). Washington, DC: American Psychological Association.

Stroebe, M. S., \& Schut, H. A. W. (1999). The dual process model of coping with bereavement: Rationale and description. Death Studies, 23, 197-224.
Stroebe, M. S., \& Stroebe, W. (1993). The mortality of bereavement: A review. In M. S. Stroebe, W. Stroebe, \& R. O. Hansson (Eds.), Handbook of bereavement: Theory, research, and intervention (pp. 175-195). Cambridge: Cambridge University.

Stroebe, M., Stroebe, W., \& Schut, H. (2001). Gender differences in adjustment to bereavement: An empirical and theoretical review. Review of General Psychology, 5, 62-83.

Stroebe, W., \& Stroebe, M. S. (1987). Bereavement and health: The psychological and physical consequences of partner loss. Cambridge: Cambridge University.

Stroebe, W., Schut, H., \& Stroebe, M. (2005). Grief work, disclosure and counseling: Do they help the bereaved? Clinical Psychology Review, 25, 395-414.

Stroebe, W., Stroebe, M., \& Domittner, G. (1988). Individual and situational differences in recovery from bereavement: A risk group identified. Journal of Social Issues, 44, 143-158.

Stroebe, M. S., Stroebe, W., \& Schut, H. (2005). Attachment in coping with bereavement: A theoretical integration. Review of General Psychology, 9, 48-66.

Vachon, M., Rogers, J., Lyall, W., Lancee, W. J., Sheldon, A. R., \& Freeman, S. J. (1982). Predictors and correlates of adaptation to bereavement. American Journal of Psychiatry, 139, 998-1002.

Walter, T. (1999). On bereavement: The culture of grief. Buckingham: Open University.

Wijngaards-de Meij, L., Stroebe, M., Schut, H., Stroebe, W., van den Bout, J., van der Heijden, P., et al. (2005). Couples at risk following the death of their child: Predictors of grief versus depression. Journal of Consulting and Clinical Psychology, 73, 617-623.

Wijngaards, L., Stroebe, M., Schut, H., Stroebe, W., van den Bout, J. van der Heijden, P., et al. (submitted). Patterns of attachment and parents' adjustment to the death of their child.

Winchester-Nadeau, J. (2001). Meaning making in family bereavement: A family systems approach. In M. S. Stroebe, R. O. Hansson, W. Stroebe, \& H. Schut (Eds.), Handbook of bereavement research: Consequences, coping, and care (pp. 329-347). Washington, DC: American Psychological Association.

Wortman, C., \& Silver, R. (2001). The myths of coping with loss revisited. In M. Stroebe, R. O. Hansson, W. Stroebe, \& H. Schut (Eds.), Handbook of bereavement research: Consequences, coping and care (pp. 405-429). Washington, DC: American Psychological Association.

Zisook, S., Shuchter, S., Irwin, M., Darko, D., Sledge, P., \& Resovsky, K. (1993). Bereavement, depression, and immune function. Psychiatry Research, 52, 1-10. 